\title{
O DIREITO À INTEGRAÇÃO DO TRABALHO E O SINDICALISMO NO MERCOSUL
}

\section{TRADE UNIONISM AND THE RIGHT TO INTEGRATE LABOR IN MERCOSUR}

Joice Duarte Gonçalves Bergamaschi ${ }^{1}$ Tânia Lobo Muniz ${ }^{2}$ Lourival José de Oliveira ${ }^{3}$

Resumo: A busca por expansão e desenvolvimento da economia fez com que os países se aglutinassem em Blocos Regionais para ter maior poder de barganha no desenrolar das atividades comerciais. $O$ cenário da regionalidade, marcado pela livre circulação de bens, mercadorias e capitais, originariamente se mostra relutante a assumir uma face que também se traduza em bem-estar social para as populações diretamente envolvidas, o que ameaça pontualmente o futuro da proteção das relações de trabalho. A partir daí, a pesquisa se utiliza do método dedutivo para perpassar os desafios do sindicalismo no Mercosul a fim de concluir que o movimento tem apresentado importantes propostas para enfrentar a relação capital-trabalho na atual conjuntura econômica, trazendo significativas contribuições para o direito à integração do trabalho no âmbito do Bloco Econômico formado pelos países do Cone Sul. O estudo se mostra relevante porque o fortalecimento da atuação sindical no Mercosul possibilita a internacionalização da disputa entre a apropriação dos meios de produção e a justa distribuição da riqueza socialmente produzida.

Palavras-chave: Sindicalismo. Blocos econômicos. Mercosul. Integração do trabalho.

Abstract: The search for expansion and development of the economy caused the countries to join in Regional Blocks to have greater bargaining power in the conduct of commercial activities. The scenario of regionality, marked by the free movement of goods, goods and capital, is originally reluctant to assume a face that also translates into social well-being for the populations directly involved, which punctually threatens the future of the protection of relations of job. From there, the research uses the deductive method to overcome the challenges of trade unionism in Mercosur in order to conclude that the movement has presented important proposals to face the capital-labor relation in the current economic conjuncture, bringing significant contributions to the right to integration of work within the economic bloc formed by the countries of the Southern Cone. The study is relevant because the strengthening of trade union activity in Mercosur allows the internationalization of the dispute between the appropriation of the means of production and the fair distribution of the socially produced wealth.

Keywords: Syndicalism. Economic blocks. Mercosur. Integration of work.

Recebido em 23 de junho de 2018 Avaliado em 12 de setembro de 2018 (AVALIADOR A) Avaliado em 23 de novembro de 2018 (AVALIADOR B) Avaliado em 2 de dezembro de 2018 (AVALIADOR C) Aceito em 11 de dezembro de 2018

\footnotetext{
1 Bacharel em Direito pela Universidade Paranaense; Mestranda em Direito Negocial pela Universidade Estadual de Londrina; Rodovia Celso Garcia Cid, Pr 445 Km 380, Caixa Postal 10.011, Campus Universitário, 86057-970, Londrina, Paraná, Brasil; https://orcid.org/0000-0001-5179-8874; joicedto@hotmail.com

2 Doutora em Direito pela Pontifícia Universidade Católica de São Paulo; Professora no Programa de Mestrado em Direito Negocial da Universidade Estadual de Londrina; https://orcid.org/0000-0003-1414-362X; lobomuniz@gmail.com

3 Doutor em Direito das Relações Sociais pela Pontifícia Universidade Católica de São Paulo; Professor na Universidade Estadual de Londrina; Professor nos Programas de Mestrado e Doutorado em Direito da Universidade de Marília; https://orcid. org/0000-0001-6700-0820; lourival.oliveira40@hotmail.com
} 


\section{Introdução}

fenômeno da globalização ajuda a remover barreiras à livre circulação de capitais, oferecendo largo campo a estratégias que deem continuidade ao processo de acumulação. A busca por consolidação e espaço no mercado mundial globalizado determinou a formação de Blocos Econômicos Regionais, no âmago de fortalecer a economia e potencial competitivos dos Estados participantes, principalmente para fazer frente à forte influência das empresas transnacionais, que reivindicam, cada vez mais, políticas de desregulação e liberalização dos mercados, para facilitar a mobilidade de bens e capitais.

À medida que avançam os processos de integração para formação de zonas regionais de livre comércio, cresce a necessidade de dar amparo à questão social. Isso acontece porque a liberdade comercial dentro dos Blocos Econômicos tem grande potencial impactante sobre a qualidade dos empregos oferecidos, vez que as os atores comerciais comumente se apoderam de vantagens relativas à oferta de baixos salários, relações contratuais informais e, mesmo, regras ambientais menos rigorosas.

Neste diapasão, a pesquisa se utiliza de metodologia consistente em revisão bibliográfica e análise de normativas internacionais relevantes a fim de verificar como a trasnacionalização da atuação sindical é importante para a defesa da integração do trabalho no âmbito do Mercado Comum dos Países do Sul (Mercosul), já que as relações laborais são diretamente afetadas pelas políticas dos blocos de liberalização do comércio regional.

Estudar a atuação sindical na defesa da integração do trabalho no Mercosul se mostra relevante porque a otimização da contratação regional no âmbito das relações de trabalho não é contraditória à contratação de âmbito nacional. Em verdade, a internacionalização do sindicalismo tem por escopo fortalecer as organizações sindicais internas dos países, dando a elas amparo e proteção de normativas oriundas de organizações internacionais. A atuação do sindicalismo na defesa de melhores condições de trabalho no Mercosul assume, ainda, grande importância para fins de inserir na política do Bloco Econômico estratégias de crescimento e distribuição dos ganhos da produtividade, a fim de dirimir a evidente exclusão social no contexto latino-americano.

\section{A formação dos blocos econômicos regionais e a questão social}

No final da década de 1970 do Século XX o volume do comércio internacional multiplicouse exponencialmente, em razão da expansão de fenômenos como o toyotismo e a transição à 
acumulação flexível, ${ }^{4}$ que incutiram num retrocesso à políticas estatais protecionistas. ${ }^{5}$ Igualmente, a intensificação do fenômeno da globalização, acelerada pelo progresso técnico e expansão dos meios de comunicação, impulsionou os processos produtivos e elevou a pressão pela consolidação de um mercado mundial, pois empresas tornavam-se transnacionais e reclamavam dos Estados a adoção de políticas que facilitassem o avanço da economia para áreas transfronteiriças. ${ }^{6}$

- mercado globalizado exigiu dos processos produtivos um patamar de extrema interdependência, o que demandava dos países uma atuação a nível extraterritorial que lhes permitisse concorrer na busca pelo lucro e, por isso, gradualmente passaram a depender de mercados externos. Não obstante, as importações e as exportações passaram a representar uma fatia cada vez mais expressiva do Produto Interno Bruto (PIB) dos países (FERREIRA; ZEETANO, 1998, p. 229), fato determinante para a associação dos diferentes Estados e formação dos Blocos Econômicos Regionais.

Assim, a fim de atender demandas geopolíticas e econômicas específicas, os acordos regionais encontraram solo fértil e proliferaram-se de maneira espantosa. No final dos anos 1990 do século XX, segundo Dupas (1999, p. 132), cerca de 60\% do comércio mundial ocorria dentro desses acordos regionais de livre comércio, como a União Europeia (UE), a Cooperação Econômica da Ásia Pacífico (APEC), a Associação de Nações do Sudoeste Asiático (ASEAN), o Acordo de Livre Comércio da América do Norte (NAFTA) e o Mercado Comum do Sul (Mercosul) e, simultaneamente, a maior parte dos países envolvidos nestes blocos participava também das negociações multilaterais do Acordo Geral sobre Tarifas Aduaneiras (GATT) e integrava a Organização Mundial do Comércio (OMC).

O avanço das políticas de blocos tem efeitos diretos sobre as decisões estratégicas das empresas na formação de cadeias globais e sobre suas políticas de investimento. Dupas (1999, p. 64) destaca que a fundação da União Europeia (UE), por exemplo, propiciou um expressivo aumento do investimento direto intraeuropeu, no esforço das corporações de racionalizar sua produção em busca de economias de escala e eficiência, além de representar um market share europeu contra a investida de outros concorrentes internacionais.

No caso do NAFTA, composto pelo México, Canadá e Estados Unidos, os efeitos foram diferentes. As parcelas de investimento de empresas norte-americanas dirigidas ao México e ao Canadá declinaram, provavelmente por conta das quedas de barreiras terem possibilitado às empresas exportarem a esses países a partir dos Estados Unidos (DUPAS, 1999, p. 64). Isso demonstra

\footnotetext{
4 Segundo Behring (2008, p. 34 e 38), "no mundo da produção e do trabalho difundiu-se nos anos 1980 o modelo japonês o ohnismo/toyotismo, fundado nas possibilidades abertas pela introdução de um novo padrão tecnológico: a revolução microeletrônica. É a chamada produção flexível, que altera o padrão rígido fordista [...]". Em síntese, "[...] a palavra de ordem da reestruturação produtiva diz respeito a alcançar o máximo de produtividade da força de trabalho para ampliar a taxa de mais valia e de lucro, mas sem preocupação com o crescimento e os efeitos de barbarização da vida social daí decorrentes."

5 Para Behring (2008, p. 59), "As políticas neoliberais comportam algumas orientações/condições que se combinam, tendo em vista a inserção de um país da dinâmica do capitalismo contemporâneo, marcada pela rentabilidade do capital, por meio da reestruturação produtiva e da mundialização: atratividade, adaptação, flexibilidade e competitividade. In: Behring, E. Brasil em contrarreforma: desestruturação do Estado e perda de direitos."

6 Neste sentido, Oliveira (2015) aduz que "[...] a transnacionalização da economia e, por conseguinte das empresas, seja na produção de bens ou na prestação de serviços, está associada diretamente a adoção e aperfeiçoamento do modelo toyotista de organização do trabalho."
} 
claramente que os benefícios decorrentes dos processos de aglutinação em Blocos Econômicos podem não ser auferidos igualmente por todos os países componentes.

No Mercosul, o comércio entre os países do bloco cresceu rapidamente, sendo que, de 1990 a 1997, as empresas transnacionais já representavam 60\% do comércio intraregional, havendo expansão dos investimentos diretos mesmo por empresas americanas, asiáticas e europeias (DUPAS, 1999, p. 65), atraídas pelas facilidades oferecidas pelos núcleos de produção local.

Embora haja o risco de que alguns Estados se beneficiem mais do processo de integração do que outros, o horizonte de expansão da economia mundial faz com que os países persigam estratégias que os coloquem neste jogo de abertura comercial protegida pelas políticas econômicas dos Blocos Regionais. Nesse sentido:

Através de investimentos diretos atraídos pelas facilidades dos blocos regionais, os países em desenvolvimento podem se beneficiar desse processo de fragmentação, especialmente do outsourcing de seguimentos trabalho-intensivos e padronizados do processo de produção. Em vários casos, o incremento comercial estimulado pelos novos investimentos acaba significando maiores exportações de bens de capitais pelo país de origem dos investimentos e um razoável estímulo, via global sourcing, para exportações de insumos intermediários dos países hospedeiros para os investidores. (DUPAS, 1999, p. 65).

Importante ressaltar que, embora implique na flexibilização da soberania dos países, para Oman (1994, p. 17) quando a regionalização estimula a concorrência internamente ou entre países membros do bloco e propicia a integração profunda das políticas nacionais, ela também fortalece a soberania coletiva dos Estados membros em face do mercado global, o que permite uma competitividade regional em relação ao resto do mundo. A aglutinação dos Estados em prol da formação de um ente regional com potencial econômico mais forte ganha destaque, principalmente por conta da franca possibilidade de desenvolvimento econômico dos países envolvidos.

Noutra banda, se melhorar o desempenho econômico dos países sempre foi o objetivo principal da formação dos Blocos Regionais, claramente, fins de bem-estar social nunca estiveram no topo das negociações, mesmo porque, os sindicatos nunca foram os principais atores junto da discussão da regionalização. Tomando-se como exemplo a formação da União Europeia e do Mercosul, Costa (2003, p. 111) destaca que "[...] uma constatação mais ou menos óbvia a respeito quer da União Europeia (UE), quer do Mercado Comum do Sul (Mercosul), é a de que as organizações sindicais não estiveram na linha da frente da negociação de tais projetos de integração regional." A questão social, entretanto, também deve ter o seu espaço regional fortalecido, vez que representa o bem-estar das pessoas que vivem dentro daquela comunidade.

déficit de atuação do sindicalismo no âmbito de formação dos Blocos Econômicos Regionais pode ser justificado porque, seguramente, as bases reais dos processos de integração são econômicas e comerciais, sem o que, esses processos simplesmente não se sustentariam na prática. Almeida (1999, p. 18) enfatiza que a questão social se encontrava totalmente ausente das experiências 
declaradamente livre-cambistas do tipo do NAFTA ou das uniões aduaneiras ainda incipientes como o Mercosul, como prova a necessidade de intensos debates para fixação da chamada "cláusula social" e de um "Protocolo Sociolaboral" de direitos trabalhistas básicos. A dinâmica da política econômica dos Blocos Regionais outorga flagrante facilidade para a circulação de capitais, mas evidente embaraço para a proteção e circulação de trabalhadores dentro dos blocos, o que evidencia a dificuldade de se incorporar a dimensão social aos processos de integração.

O histórico de frustrações sociais no âmbito dos Blocos Regionais também é alimentado pelo fato de que, raramente, associações patronais, sindicatos de trabalhadores e políticas estatais partilham da mesma concepção sobre o que significaria atribuir uma dimensão social a seus processos concretos de integração (ALMEIDA, 1999, p. 19). O desacordo não se mostra desarrazoado, tendo em conta a dificuldade de formação de uma consciência comunitária entre os ordenamentos dos diferentes países integrantes dos Blocos Econômicos Regionais, somado ainda a evidente constatação de que a formação de regimes previdenciários e de proteção laboral à nível regional incidiria em flexibilização da normativa interna dos Estados envolvidos.

Costa (2005, p. 189) faz um comparativo entre a atuação sindical no contexto da União Europeia (UE) e do Mercosul, destacando que:

Não obstante a UE e o Mercosul evidenciarem hoje distintos graus de consolidação institucional e não obstante o nascimento do sindicalismo europeu ter sido mais precoce do que o surgimento do sindicalismo sul americano, vários problemas comuns ao sindicalismo dos dois quadrantes podem ser identificados, para além da referida secundarização dos atores sindicais em ambos os blocos.

Embora destaque que o sindicalismo transnacional no âmbito do bloco europeu seja mais amadurecido que o sindicalismo sul americano, o Autor sublinha que há dificuldades semelhantes. Entre os pontos convergentes à dificuldade de transnacionalização do sindicalismo no contexto da UE e do Mercosul, está o fato de que as raízes sindicais são predominantemente nacionais, com preponderância do espaço de atuação sindical nacional, havendo, ainda, diferenças entre países em matéria legislativa, resultantes da inexistência de sistemas legais uniformes, além, é claro, da dificuldade de formação de uma consciência laboral comunitária (COSTA, 2005, p. 189-190).

Embora obstaculizada, a atuação sindical transnacional no âmbito dos Blocos Econômicos Regionais ganha cada vez mais importância, pois as políticas adotadas têm efeitos significativos sobre as relações de trabalho e também sobre a expansão da exclusão social. Com efeito, Dupas (1999, p. 139) enaltece que as políticas de construção dos Blocos Regionais influenciam diretamente as decisões estratégicas das empresas transnacionais na formação de cadeias globais, que ampliam consideravelmente a oferta de emprego nos países a que direcionam seus investimentos. Entretanto, nestas zonas, o trabalho apresenta baixa ou nenhuma qualificação e relações sindicais frágeis, com trabalhadores submetendo-se a longas jornadas, trabalho noturno, alta rotatividade e pouca estabilidade, a partir do que, as principais tendências são: 
- Redução da geração de empregos qualificados e formais por investimento direto adicional;

- Contínua flexibilização da mão-de-obra em todos os níveis, no sentido de transformá-la em componente radicalmente variável do custo final dos produtos globais;

- Clara inter-relação entre agentes econômicos formais e informais na medida em que se caminha para as bases das cadeias produtivas, abrigando o trabalho informal e low wage. (DUPAS, 1999, p. 139).

Portanto, se por um lado a dinâmica da globalização e regionalização econômica possibilita o deslanchar do fracionamento das cadeias produtivas, por outro lado, impulsiona a precarização do trabalho, já que a elevação do número de postos de trabalho não está acompanhada de garantias de formalidade e elevação de renda. Com a abertura da economia, os sindicatos são parte de um jogo político mais complexo e difícil, que escapa aos limites do sistema de relações de trabalho que durante décadas constituiu o elemento vital de mobilização dos trabalhadores, quando a inflação condicionava a ação sindical através da negociação de reajustes salariais e a capacidade de pressão era exercida por meio de greves (VEIGA, 1999, p. 188).

No plano regional, a atuação sindical ganha um novo papel, não orientado para uma lógica imediatista onde a negociação coletiva por reivindicações salariais tenha resultados instantâneos. $\bigcirc$ movimento sindical transnacional impera atuação no presente para atingir objetivos a longo prazo, o que não o torna menos relevante, principalmente para a defesa dos interesses das classes laborais dos países mais pobres, comumente na periferia do capitalismo global.

\section{2 atuação sindical no Mercosul}

Os acordos que preveem a integração dos países em Blocos Econômicos Regionais representaram a grande virada para a economia dos Estados do final do Século XX. Entretanto, dado o potencial de impacto sobre o trabalho que a liberalização da economia a nível regional pode causar, a atuação sindical também ganhou espaços transfronteiriços no âmago de fazer frente à tendência dos acordos econômicos regionais de estimular modificações de caráter liberalizante na legislação dos países, o que pode determinar a perda de direitos sociais adquiridos há décadas.

Inicialmente, cabe ressaltar que sempre existiram instâncias de representação sindical que coordenavam ações comuns entre diferentes confederações e centrais sindicais no mundo. Contudo, tais organizações não dispunham de grande autonomia para tomada de decisões que não fossem acompanhadas de perto pelos sindicatos e centrais nacionais, como discorre João Veiga (1999, p. 174):

A Confederação Internacional de Organizações Sindicais Livres (CIOSL) e os secretariados internacionais, a Confederação Mundial do Trabalho (CTM), a Confederação Europeia de Sindicatos (CES) e outras organizações regionais como a Organização Regional Interamericana de Trabalhadores (Orit) sempre atuaram no sentido de tentar organizar a ação sindical em escala internacional. No entanto, 
a divisão de poder entre essas organizações respeitava os limites impostos pela Guerra Fria. Ademais, elas sempre se ressentiram de uma articulação mais sólida junto a outros atores sociais e, na realidade, essas organizações não dispunham de grande autonomia para tomar decisões que não fossem acompanhadas de perto pelos sindicatos e centrais nacionais.

A intensificação do fenômeno da globalização e a formação de Blocos Econômicos Regionais de livre comércio, como a antiga Comunidade Econômica Europeia (CEE) e o Mercado Comum do Sul (Mercosul), determinaram a maior mobilização internacional dos trabalhadores no âmago de pressionar os governos e as empresas a apoiarem as causas de seu interesse, bem como criar mecanismos que minimizassem os efeitos negativos dos acordos de comércio sobre o campo social. Estas preocupações dispararam a necessidade de criação de organismos sindicais internacionais mais fortes, com maior poder de representação, negociação e decisão.

Diante da regionalização, o movimento sindical constatou que crises e mudanças não podem ser enfrentadas somente por meio de soluções negociadas setorialmente, por meio de intervenções nacionais. Os novos desafios trazidos pela regionalização do livre comércio impuseram aos sindicatos um pensar e um agir como uma classe trabalhadora também regionalizada, para estabelecer novos parâmetros de relações com os Estados e com os empresários, os quais são integrados e subordinados a decisões supranacionais (ZYLBERSTAJN et al., 1996, p. 7).

No que concerne ao Mercado Comum dos Países do Cone Sul, a atuação sindical transnacional ganhou força após a criação da Coordenadoria de Centrais Sindicais do Cone Sul (CCSCS), em 1986, pelos países membros do Mercosul, mais o Chile e a Bolívia. A atuação da CCSCS tem importante papel na luta dos trabalhadores no contexto do Mercosul e sua relação com a América Latina, pois tem a responsabilidade de reivindicar e manter os direitos laborais adquiridos em épocas anteriores, além de discutir os rumos das relações laborais diante do processo integracionista.

Atualmente, a CCSCS é composta por 12 centrais sindicais: Plenário Intersindical de Trabajadores-Convención Nacional de Trabajadores (PIN-CNT2), do Uruguai; Confederación General de Trabajo (CGT3) e a Central de Trabajadores (CTA4), da Argentina; Central Única de Trabalhadores (CUT5), Força Sindical (FS6), Confederação Geral dos Trabalhadores (CGT) e Central Autônoma dos Trabalhadores (CAT), do Brasil; Central Unitária de Trabajadores (CUT7), Central Nacional de Trabajadores (CNT8) e Confederación Paraguaya de Trabajadores (CPT9), do Paraguai; Central Obrera Bolivariana (COB10), da Bolívia, e; Central Unitária de Trabajadores (CUT11), do Chile (COORDENADORIA DE CENTRAIS SINDICAIS DO CONE SUL, 2018).

Importante discorrer que a consolidação da CCSCS, ocorreu somente com a intensificação do processo de integração regional, pois, à medida que os Estados avançavam na atribuição de importância ao processo de integração no hemisfério sul, os atores sociais tiveram que adequar-se, buscando dele participar como forma de resguardar as próprias posições de classes, coorporativas ou setoriais (CHALOULT, 1999, p. 61). Assim, ante a evidente importância da atuação sindical na 
perspectiva internacionalista, no interesse nacional ou local, a CCSCS envolveu-se diretamente no processo de integração regional a partir de 1992 (VIGEVANI, 1998, p. 20).

A partir da criação do MERCOSUL, a CCSCS percebeu que o processo de integração no Cone Sul implicava desafios inusitados para o movimento sindical, não mais correspondente a uma atuação tradicional (VIGEVANI; MARIANO, 1999, p. 107), o que explica o fato de que, nos primeiros anos, a CCSCS teve sua atuação voltada a questões sociais que não estritamente relativas ao desenvolvimento do trabalho no Mercosul. Neste sentido:

Durante seus primeiros anos de atividade, a CCSCS concentrou sua atenção nos temas referentes à democratização e às políticas econômicas implementadas pelos países do Cone Sul e da América latina em geral, para controlar a inflação e promover o crescimento e desenvolvimento econômico, num contexto em que a crise da dívida era uma questão central. Nesse sentido, um dos principais motivos de criação da CCSCS foi a desconfiança que as centrais sindicais sentiam em relação às políticas que estavam sendo adotadas pelos seus governos, e aos seus impactos sobre o mercado de tralho. Como essas políticas são tomadas individualmente por cada país e variam nos seus conteúdos, a possibilidade de atuação conjunta das centrais integrantes da CCSCS era limitada, estimulando-se a diversidade de interesses dessas centrais. (VIGEVANI; MARIANO, 1999, p. 106).

Com efeito, se políticas econômicas governamentais poderiam interferir diretamente nas relações de trabalho no âmbito do Mercosul, o sindicalismo precisava reforçar a CCSCS como instituição internacional que melhor desse amparo aos interesses das questões sociais discutidas. $\bigcirc$ resultado dessa mudança de perspectiva no sindicalismo originou um novo padrão de relacionamento entre as centrais sindicais da região, permitindo que as diferenças fossem atenuadas à medida que eram criados interesses e valores compartilhados no âmbito do Mercosul, em um movimento que, no final do Século XX, se mostrava bastante articulado (VIGEVANI; MARIANO, 1999, p. 107).

Assim, de posse do espírito de necessidade de proteção laboral regional, em 1996, a CCSCS entregou aos presidentes dos países do Mercosul documento com as principais reivindicações sindicais regionais, que consistiam na luta por: plena democratização das instâncias de decisão, retomada da discussão e implementação da Carta de Direitos Sociais do Mercosul, criação de um Fundo de Apoio à Reconversão Produtiva e Requalificação Profissional, constituído com recursos provenientes da ampliação dos fluxos de comércio, e o reconhecimento dos sindicatos no processo de negociação coletiva (STUART, 1999, p. 128). Estes pontos foram incorporados à Declaração Conjunta do Movimento Sindical e Organizações Sociais, apresentada na "Cúpula dos Povos das Américas", em Santiago, no Chile, em 1998, por ocasião da II Reunião de Cúpula dos Chefes de Estado das Américas (STUART, 1999, p. 128).

Em que pese a importância dos interesses defendidos, muitos objetivos propostos pelos sindicatos terminavam não sendo atendidos, em razão de sua pouca força de barganha a nível internacional. Não obstante, a CCSCS também se destacou no ativismo pela criação de um Subgrupo de Trabalho (SGT) tripartite, no qual os representantes dos trabalhadores pudessem negociar com 
os empresários e com o Estado, discutindo e aprofundando juntos temas relacionados ao interesse do trabalho e do capital, além de defender a elaboração de uma Carta de Direitos Fundamentais do Mercosul, a ratificação pelos países integrantes do Mercosul de um pacote das Convenções mais importantes da Organização Internacional do Trabalho (OIT) e a assinatura da Declaração Sociolaboral do Mercosul de 1998 (BRUNELLE; CHALOULT, 1999, p. 166).

Contemporaneamente, a atuação da Coordenadoria de Centrais Sindicais do Cone Sul (CCSCS) ganhou destaque após o êxito na aprovação da Declaração Sociolaboral do Mercosul de 2015, negociada e assinada em Brasília, em reunião realizada em 17 de julho de 2015. A declaração de 2015 revisou a antiga Declaração Sociolaboral do Mercosul assinada em 1998, sedimentando direitos individuais, coletivos e ambientais do trabalho.

A Declaração Sociolaboral do Mercosul de 2015 representa, atualmente, o principal documento de defesa de direitos na seara social do Mercosul e tem fundamental importância para a atuação das centrais sindicais, na medida em que determina que as práticas nacionais devam convergir para com os fundamentos exarados em seu texto. Dentre as mais importantes prescrições, destaca-se a alteração inibidora de violações, já que pessoas físicas e jurídicas que não cumprirem as previsões dispostas não poderão participar de projetos financiados pelo Fundo para a Convergência Estrutural do Mercosul (art. 31, item 4).

Com efeito, embora relevante, a transnacionalização do sindicalismo no âmbito do Mercosul encontra grandes dificuldades, seja porque há preponderância do espaço de atuação sindical nacional, seja porque há necessidade de grandes recursos financeiros para suportar uma ação transnacional. Costa (2005, p. 190-191) ainda destaca obstáculos relacionados à necessidade de lidar com distintos interesses sindicais consolidados nacionalmente, à inexistência de sistemas legais uniformes, a não uniformidade de adesão às convenções da Organização Internacional do Trabalho (OIT), bem como os "ritmos de integração regional", pois a criação de direitos iguais entre os países membros do Mercosul depende da progressão deste a caminho de um verdadeiro "mercado comum".

A inclinação das centrais sindicais do Cone Sul, reunidas na Coordenadoria de Centrais Sindicais do Cone Sul (CCSCS), é no sentido de reforçar o componente social que tem faltado ao Mercosul. Daí porque, para além dos temas econômicos e produtivos, a CCSCS também tem apostado em temas sociais e laborais, apresentando propostas como: a reinstalação do debate sobre a Carta dos Direitos Sociais do Mercosul, para garantia de iguais condições de trabalho e de direitos laborais nos países do Mercosul; condições efetivas de funcionamento do Observatório do Mercado de Trabalho do Mercosul, de modo que este possa gerar indicadores próprios e confiáveis sobre os diferentes impactos dos processos de integração sobre o mercado de trabalho; uma maior harmonização legislativa em matéria social, e; a defesa de um Mercosul que, mais de que uma união aduaneira, promova reais mecanismos de integração, permitindo a livre circulação de trabalhadores entre os países do bloco (COSTA, 2005, p. 200-201). 
Em verdade, o esforço do movimento sindical de articular ações que transcendam as fronteiras nacionais é processo em estágio embrionário porque os Estados ainda continuam a ser o espaço principal para defesa dos direitos e interesses da sociedade civil (STUART, 1999, p. 129). Entretanto, o mercado, para além da questão econômica, também se constitui relação social, que demanda a construção de novos projetos políticos e sociais, compatíveis com as transformações advindas do movimento de regionalização e globalização nos mercados, culturas e pessoas.

Apesar das dificuldades, a importância da atuação sindical no Mercosul não pode ser menosprezada, porque dela depende a defesa de questões sociais relevantes. Hermes Augusto Costa (2005, p. 206) destaca que um dos caminhos para o sindicalismo do Mercosul depende de um grande trabalho de cooperação entre as centrais sindicais do Cone Sul e a Organização Regional Interamericana de Trabalhadores (ORIT), para o fim de possibilitar um intercâmbio sobre os temas da integração. Além disso, impera também a necessidade de fomentar um maior diálogo e cooperação entre o sindicalismo e outras organizações da sociedade civil, para superação das fronteiras da própria classe trabalhadora e do movimento sindical (COSTA, 2005, p. 207).

Estimular a articulação entre sindicatos e outras organizações da sociedade civil não é tarefa fácil, mas, por isso mesmo, não é algo que pode ser deixado de lado, como prevê Costa (2005, p. 207):

Este desafio da articulação entre sindicatos e outras organizações da sociedade civil não é um desafio fácil. No entanto, e precisamente pelo fato de não ser fácil, ele não deve perder importância no seio de organizações sindicais como a CCSCS. Não se trata de substituir os papéis do movimento sindical pelos de outras organizações sociais e vice-versa, mas tão-só de incentivar o sindicalismo do Mercosul a proceder a uma renovada visão do mundo e dos seus problemas que não esteja exclusivamente assente em interesses sindicais.

O diálogo entre as forças sindicais do Mercosul e as organizações da sociedade civil tem grande relevância porque é sabido que elas têm maior proximidade para com os problemas e anseios das comunidades. A legitimidade e o fortalecimento do sindicalismo transnacional dependem, então, da proximidade entre os anseios sociais e os objetivos da luta sindical, além, é claro, do apoio das autoridades do Mercosul para obter sucesso, sobretudo, na demanda pelo reconhecimento do direito à integração do trabalho na esfera regional.

\section{0 direito à integração do trabalho no Mercosul}

É sabido que o processo de integração para o livre comércio entre os países do Cone Sul sempre teve por objetivo possibilitar a livre circulação de bens e mercadorias. Com efeito, a criação do Mercosul não levou em conta a livre circulação também dos trabalhadores ou a sugestiva constatação de que criar-se-ia, ao menos, um direito à integração do trabalho, para fazer frente ao 
grande potencial impactante que a liberdade comercial dentro do bloco teria sobre a qualidade dos empregos oferecidos.

Na Europa, a livre circulação de trabalhadores tem amparo desde o Tratado de Paris (1951) que criou a Comunidade Europeia do Carvão e do Aço (CECA), sendo que, em 1957, o Tratado de Roma que constituiu a Comunidade Econômica Europeia (CEE) trouxe em seu corpo um título específico destinado à "Política Social", com o objetivo de promover facilidades de emprego e mobilidade geográfica e profissional para os trabalhadores (ALMEIDA, 1999, p. 24). Como se vê, desde o início da ideia de aglutinação econômica dos países europeus, já havia grande esforço para consolidar a questão social, que ainda recebeu o amparo, em 1989, de uma Carta Comunitária de Direitos Sociais Fundamentais.

Já no Mercosul, assim como no NAFTA, há uma perspectiva de circulação do "trabalho" e não necessariamente de trabalhadores, como esclarece o artigo $1^{\circ}$ do Tratado de Assunção (MERCOSUL, 1991), que dispõe que haverá "livre circulação de bens, serviços e fatores produtivos entre os países", ou seja, criou-se um universo de circulação de coisas e não de livre movimentação de pessoas, ainda que sob a roupagem de trabalhadores (ALMEIDA, 1999, p. 26). A restrição institucional do Mercosul reflete assimetrias que não podem ser corrigidas pela simples letra dos tratados, mas pode ser explicada por meio do evidente receio de que, à época, no ano de 1991, houvesse o deslocamento em massa dentro dos países componentes no Bloco Econômico sul americano, já que nenhum deles dispunha de recursos suficientes para absorver mesmo a mão-de-obra excedente interna.

Neste sentido, dispõe Almeida (1999, p. 27):

Ainda que se possa considerar que a economia dos Estados Unidos, no caso do NAFTA, detém uma maior capacidade de absorção de "excedentes" de mão-deobra mexicana - incorporados de forma legal ou ilegal a seu mercado laboral nacional - do que, por exemplo, no quadro do Mercosul, a Argentina em relação à "exportação" potencial de trabalhadores brasileiros sem qualificação formal, tal perspectiva assumiria, em se tratando do pequeno Uruguai, ares de "catástrofe social", para não qualifica-la como uma questão de "segurança nacional". De fato, o problema pode ser melhor avaliado se se lembrar que toda a população uruguaia representa o equivalente a um simples bairro da aglomeração paulistana, ou, se quisermos, de uma de suas periferias mais pobres. A possibilidade de que massas de "brasileiros miseráveis" pudessem invadir incontroladamente o território uruguaio à busca de melhores condições de vida ou até o espaço social paraguaio, atraído pelo salário mínimo formalmente superior ali vigente, pode ter atuado como um impedimento à inscrição desse "direito" de circulação na terra do Tratado de Assunção pelos fouding fathers do processo sul-americano.

Já no caso europeu, a tutela da questão social não se preocupava com o deslocamento maciço de trabalhadores dentro do Bloco Econômico, mesmo porque os fluxos de imigrantes dentro do próprio continente europeu sempre foram modestos. ${ }^{7}$ Não obstante, o modelo europeu, por estar

\footnotetext{
Neste sentido, Paulo Roberto de Almeida aduz que "Quando tal possibilidade foi incluída no corpo do tratado europeu não se previa um deslocamento maciço - como de fato não ocorreu - de massas de trabalhadores dos países envolvidos entre si. Os fluxos maciços de pessoas foram bastante modestos, à exceção dos imigrantes pobres do Mezzogiorno italiano para
} 
numa evoluída etapa do processo de integração, tem grande importância referencial para os países do Cone Sul, porque possui experiência histórica mais avançada neste terreno.

Cabe destacar ainda que, desde o início, a Comunidade Econômica Europeia (CEE) instituiu um Comitê Econômico e Social que permitiu a incorporação dos diferentes agentes sociais nos debates em curso sobre as políticas a serem adotadas no âmbito comunitário, o que permitiu a criação do Fundo Social Europeu, em 1954, e do Fundo Europeu de Desenvolvimento Regional, em 1975 (ALMEIDA, 1999, p. 29). Já no Mercosul, o fluxo da integração foi quase que inteiramente dominado pelo governo dos países, com moderada consulta à sociedade civil, destacando-se a criação do Foro Consultivo Econômico-social e a Declaração Sociolaboral, ambos de 1998.

Com efeito, a normatização do trabalho no âmbito do Bloco Econômico do Cone Sul via entraves desde as negociações iniciais, cujas raízes eminentemente comerciais viam na possibilidade de integração regional o fortalecimento da concorrência empresarial e mesmo a redução dos custos trabalhistas, fatores que não encontravam identificação com a proteção social central. Noutra banda, a definição de direitos comuns aos trabalhadores do Bloco Regional ganhava cada vez mais importância para garantia de que não houvesse exploração do proletariado exposto à atuação dos agentes comerciais transnacionais.

Ainda na atualidade, a devida normatização do direito à integração do trabalho no Mercosul não se encontra plenamente definida. No entanto, cumpre destacar que para dar fiel cumprimento a esta tarefa, o Mercosul deve se atentar às experiências trazidas por outros acordos de livre comércio que evidentemente criaram situações de violação quando não delimitaram a exata proteção aos direitos sociais ali envolvidos. A este despeito, Jakobsen e Martins (2004, p. 90) ressaltam que quando o NAFTA permite a livre circulação de capital, bens e serviços, mas não concede o mesmo tratamento para a circulação de mão-de-obra, cria situações de tensão e violação de direitos humanos, além de motivar imigrações ilegais.

Destarte, não é possível a integração econômica, com a consequente constituição de um mercado comum, sem que haja harmonização das legislações trabalhistas dos países que se integram (KUMMEL, 2001, p. 69). Através de uma legislação trabalhista harmonizada que trate das condições gerais do contrato de trabalho, com os direitos trabalhistas mínimos comuns aos países que passam pelo fenômeno da regionalização, é que pode se atribuir a capacidade de dirimir conflitos trabalhistas no âmbito geográfico do Mercosul (DI LORENZO, 2005, p. 83).

Kummel (2001, p. 69) discorre que a desregulamentação dos mercados de trabalho, representada pela tendência mundial em prol da flexibilização, funciona como empecilho à adoção de uma legislação trabalhista única aplicável aos países do Mercosul, que ainda conta com outros fatores impeditivos de ordem: econômica, em razão da grande disparidade entre as economias; geográfica, relacionada à extensão geográfica em que há de ser aplicada a legislação; estrutural, dada

os países setentrionais, movimento de resto contrabalançado e de certa forma largamente superado pela atração de 'não comunitários' em geral [...]" (ALMEIDA, 1999, p. 27-28). 
a inexistência de um tribunal do Mercosul especializado em matéria trabalhista, e; institucional, vinculada à dificuldade de adoção de um sistema intergovernamental de integração, sem qualquer renúncia a parcelas de soberania. Não obstante, ainda que embaraçada, a regulação do trabalho em âmbito regional vem ganhando importantes instrumentos, graças à atuação sindical no Mercosul.

Foi a atuação sindical no Mercosul que instaurou o debate pela necessidade de ter normas gerais em matéria de seguridade social para a região. Assim, no ano 1997, os países membros assinaram o chamado "Acordo Multilateral de Seguridade Social do Mercado Comum do Sul", que dispunha pontualmente que os direitos à seguridade social seriam reconhecidos aos trabalhadores que prestassem ou houvessem prestado serviços em quaisquer dos Estados Partes e que também seriam aplicados aos trabalhadores de qualquer outra nacionalidade quando fossem residentes no território de um dos Estados Partes, desde que prestassem ou houvessem prestado serviços em tais Estados Partes (MERCOSUL, 1997). O acordo de 1997 deu os primeiros sinais de efetiva proteção social aos trabalhadores no Mercosul.

A Declaração Sociolaboral do Mercosul de 1998 propunha a definição de um espaço social nas discussões do bloco, com um conjunto de garantias e o reconhecimento das Convenções da Organização Internacional do Trabalho (OIT) como fonte jurídica, no âmago de fazer com que o processo de integração econômica pudesse se traduzir em melhorias das condições de vida das sociedades nacionais e fazer um apelo para que os governos realizassem uma intervenção eficaz para garantia dos direitos dos trabalhadores (WANDERLEY, 2005, p. 227). O documento de 1998 representou a maior conquista do sindicalismo no âmbito da integração econômica dos países do Cone Sul.

Na perspectiva dos direitos coletivos, a Carta Sociolaboral do Mercosul de 1998 também destacou a relevância da atuação das centrais sindicais para a discussão dos rumos do trabalho no Mercosul. Entretanto, os encontros entre governos, trabalhadores e empresários quase sempre careciam de prosperidade, dado que a proteção das questões sociais centrais sempre sucumbia ante a alegação de que vincular direitos sociais ao acordo poderia criar precedentes protecionistas, afetar a soberania nacional e a intergovernabilidade do Mercosul (CASTRO VIEIRA, 2001, p. 216).

Em 2015, os países membros do Mercosul assinaram uma nova declaração sociolaboral. A chamada "Declaração Sociolaboral do Mercosul de 2015", revisou a declaração assinada em 1998, e representa, atualmente, o principal documento na seara de defesa do Direito do Trabalho no Mercosul. Dentre as mais importantes disposições, o documento cuidou de disciplinar que os Estados Partes devem formular e pôr em prática políticas ativas de trabalho decente e pleno emprego produtivo, promover o desenvolvimento sustentável na região, garantir a vigência do princípio de não discriminação, bem como adotar as medidas necessárias para eliminar toda forma de trabalho forçado (MERCOSUL, 2015).

A Declaração Sociolaboral do Mercosul de 2015 também contém disposições sobre a circulação de trabalhadores dentro do Bloco Econômico (Artigo $7^{\circ}$ ): 
1. Todos os trabalhadores, independentemente de sua nacionalidade, têm direito à assistência, à informação, à proteção e à igualdade de direitos e condições de trabalho, bem como direito de acesso aos serviços públicos, reconhecidos aos nacionais do país em que estiver exercendo suas atividades, em conformidade com a legislação de cada país.

2. Os Estados Partes terão em conta os direitos estabelecidos no Acordo sobre Residência para Nacionais dos Estados Partes do Mercosul, Bolívia e Chile e demais instrumentos complementares que se firmem, na medida em que façam parte dos mesmos.

3. Os Estados Partes comprometem-se a adotar e articular medidas tendentes ao estabelecimento de normas e procedimentos comuns, relativos à circulação dos trabalhadores nas zonas de fronteira e a levar a cabo as ações necessárias para melhorar as oportunidades de emprego e as condições de trabalho e de vida desses trabalhadores, nos termos dos acordos específicos para essa população, tendo como base os direitos reconhecidos nos acordos de residência e imigração vigentes. 4. Os Estados Partes comprometem-se, ademais, a desenvolver ações coordenadas no campo da legislação, das políticas laborais, das instituições migratórias e em outras áreas afins, com vistas a promover a livre circulação dos trabalhadores e a integração dos mercados de trabalho, de forma compatível e harmônica com o processo de integração regional. (MERCOSUL, 2015).

Vê-se que a Declaração Sociolaboral do Mercosul de 2015 cuidou de firmar o compromisso de que os Estados Partes devem adotar e articular medidas tendentes ao estabelecimento de normas e procedimentos comuns, relativos à circulação dos trabalhadores nas zonas de fronteira, tendo como base os direitos reconhecidos nos acordos de residência e imigração vigentes. É mais uma tentativa de dar ao Bloco Econômico roupagem de verdadeira integração regional, que mais que livre circulação de bens e capitais, também envolve a livre circulação de pessoas e de mão-de-obra. $\bigcirc$ trabalho transfronteiriço, portanto, continua entre os objetivos da integração sul americana.

No tocante a atuação sindical para defesa do direito à integração do trabalho, a Declaração Sociolaboral do Mercosul de 2015 cuidou de bem disciplinar a negociação coletiva (Artigo 17), dispondo que os empregadores ou suas organizações representativas e as organizações representativas de trabalhadores têm o direito de negociar e celebrar convenções e acordos coletivos para regular as condições de trabalho, em conformidade com as legislações e práticas nacionais dos Estados Partes, estabelecendo, ainda, que os Estados Partes têm o compromisso de facilitar mecanismos para fomentar o exercício da negociação coletiva nos diferentes âmbitos (MERCOSUL, 2015).

No âmago de dar mais força à atuação sindical, a Declaração Sociolaboral do Mercosul de 2015 também prevê a necessidade de fomentar um diálogo social (Artigo 20), em âmbito nacional e regional, instituindo mecanismos efetivos de consulta permanente entre representantes dos governos, dos empregadores e dos trabalhadores, a fim de garantir, mediante o consenso social, condições favoráveis para o crescimento econômico sustentável e com justiça social na região para melhoria dos padrões de vida de seus povos. A finalidade da consulta é incentivar a compreensão mútua e as boas relações entre as autoridades públicas e as organizações mais representativas de empregadores e de trabalhadores, bem como entre as próprias organizações, visando à promoção do 
diálogo social e à possibilidade de gerar acordos-marco de trabalho, com elementos essenciais para a consolidação de uma sociedade democrática, plural e justa (MERCOSUL, 2015).

Com efeito, a defesa do direito à integração do trabalho pelas centrais sindicais nos países membros do Mercosul se organizou em torno de temas centrais ao longo dos anos, como o respeito a legislação trabalhista dos países membros, a definição de uma carta social com amplitude de direitos e, por fim, embates sobre o deslocamento de mão-de-obra. É o que disciplina Mello e Silva (2005, p. 183):

A pauta das centrais dos países de Mercosul organizou-se então em torno de alguns temas - esse é um tópico particularmente sensível porque encerra algumas ambiguidades para os sindicatos (mais a frente será discutido com algum pormenor). Por outro lado, a definição de uma "carta social" para a região - o que parecia, à primeira vista, contraditório com o primeiro ponto. Em seguida, a elaboração de um acordo multilateral sobre o regime de previdência. Em seguida, a elaboração de um acordo multilateral sobre o regime de previdência. Por fim, um acordo sobre o deslocamento de mão-de-obra. Como se pode notar, são todos assuntos relativos a uma regulação ampla não apenas do mercado de trabalho mas daquilo que poderíamos chamar de condições de reprodução da relação salarial.

A atuação sindical no Mercosul, então, não está relacionada apenas à regulação ampla do mercado de trabalho, mas também de tudo aquilo que interfira nas condições de reprodução salarial. Assim, o sindicalismo no Mercosul ganha enorme importância para a discussão do futuro das relações sociais dentro do Bloco Econômico, principalmente para assegurar que as políticas comerciais estabelecidas garantam o equilíbrio necessário entre capital e trabalho, já que a regionalização também significa a abertura de um horizonte onde os trabalhadores possam se deslocar de um setor produtivo para o outro em busca de melhores condições de emprego e remuneração.

\section{Conclusão}

A busca por potenciais investidores e o incremento de seu mercado interno fez com que os Estados se aglutinassem em Blocos Econômicos para ter maior poder de barganha ante a atuação das empresas transnacionais. Contudo, em razão disso, muitos países têm negado respeito à sua própria legislação, já que muitos acordos econômicos envolvem a flexibilização de normas de proteção a direitos sociais fundamentais, principalmente, relativas à disciplina das relações de trabalho.

No âmbito do Mercosul, ainda que não completamente determinada a possibilidade de livre circulação de trabalhadores, o potencial de impacto da regionalização da livre circulação de bens e mercadorias sobre o deslanchar das relações produtivas e de trabalho fez crescer a preocupação para com a garantia de igualdade de direitos, boas condições de trabalho e vida digna para os operários afetados pela integração econômica dos países do Cone Sul. 
O novo cenário coloca a atuação sindical transnacional no centro das atenções, vez que a defesa de questões sociais no âmbito regional não pode provir, senão, de uma organização representativa que tenha força internacional, mesmo porque as organizações sindicais, historicamente, têm responsabilidade fundamental na busca por um meio social que seja, ao mesmo tempo, próspero e igualitário. Por conta disso, o estudo trouxe a questão social no âmbito de formação dos Blocos Econômicos Regionais, num contexto em que, embora não tenha sido o objetivo principal, a defesa do bem-estar dos trabalhadores logo ganhou destaque em razão da formação de organizações sindicais com força para atuar dentro da regionalidade.

Embora a atuação sindical no Mercosul seja mais recente que a atuação sindical no âmbito da União Europeia (UE), as conquistas auferidas desde a formação do Bloco Econômico, em 1991, não podem passar despercebidas. Pelo contrário, a revisão e edição da "Carta Sociolaboral do Mercosul", em 2015, demonstra a importância da atuação sindical transnacional, que embora obstaculizada pelas raízes predominantemente nacionais do sindicalismo, caminha no decorrer dos anos demonstrando fundamental importância à regulamentação do direito à integração do trabalho no Mercosul.

A atuação sindical transnacional deve ser ressaltada porque tem grande relevância para o êxito das lutas sociais na esfera dos Blocos Econômicos Regionais e, especificamente no âmbito do Mercosul, assume importância ainda maior, já que o seu "status" de "bloco em formação" dá grande abertura à possibilidade de inclusão da questão social na dinâmica da integração econômica regional dos países do Cone Sul, cujas populações, historicamente, estão à margem da repartição dos lucros do capitalismo global.

\section{Referências}

ALMEIDA, Paulo Roberto de. A dimensão social nos processos de integração. In: CHALOULT, Yves; ALMEIDA, Paulo Roberto de (org.). Mercosul, Nafta e Alca: a dimensão social. São Paulo: LTr, 1999.

BEHRING, Elaine. Brasil em contrarreforma: desestruturação do Estado e perda de direitos. 2. ed. São Paulo: Cortez, 2008.

BRUNELLE, Dorval; CHALOULT, Yves. Transnacionalização das práticas sindicais: quadro teórico-analítico. In: CHALOULT, Yves; ALMEIDA, Paulo Roberto de (org.). Mercosul, Nafta e Alca: a dimensão social. São Paulo: LTr, 1999.

CASTRO VIEIRA, Jeferson de. Dinâmica socioeconômica do Mercosul frente à globalização. 2001. Tese (Doutorado) - Universidade de Brasília, Brasília, DF, 2001.

CHALOULT, Yves. Relações Mercosul, Alcsa, Alca e papel do Estado. In: CHALOULT, Yves; ALMEIDA, Paulo Roberto de (org.). Mercosul, Nafta e Alca: a dimensão social. São Paulo: LTr, 1999. 
COORDENADORIA DE CENTRAIS SINDICAIS DO CONE SUL. Estatuto das centrais sindicais do cone sul. Disponível em: www.coordinadoraconosur.org. Acesso em: 30 maio 2018.

COSTA, Hermes Augusto. A integração regional do sindicalismo: uma visão comparativa Brasil-Portugal. Coimbra, Portugal: Novos Estudos, 2003.

COSTA, Hermes Augusto. O sindicalismo na UE e Mercosul: etapas e caminhos em aberto. In: ESTANQUE, Elísio et al. (org.). Mudanças no trabalho e ação sindical: Brasil e Portugal no contexto da transnacionalização. São Paulo: Cortez, 2005.

DI LORENZO, Carlos Alberto. Mercosul e o direito trabalhista. São Paulo: Alexa, 2005.

DUPAS, Gilberto. Economia global e exclusão social: pobreza, emprego, estado e o futuro do capitalismo. São Paulo: Paz e Terra, 1999.

FERREIRA, Claudia; ZEETANO, José Paulo. O Mercosul e a integração econômico regional: estágio atual da área trabalho. In: VIGEVANI, Tullo; LORENZETTI, Jorge (org.). Globalização e integração regional: atitudes sindicais e impactos sociais. São Paulo: LTr, 1998.

JAKOBSEN, Kjel; MARTINS, Renato. ALCA: quem ganha e quem perde com o livre comércio das américas. 2. ed. atual. São Paulo: Fundação Perseu Abramo, 2004.

KUMMEL, Marcelo Barroso. As convenções da OIT e o Mercosul. São Paulo: LTr, 2001.

MELLO E SILVA, Leonardo. Trabalhadores do Mercosul: uni-vos! A construção de uma voz coletiva contra-hegemônica: quando o dissenso é "pôr-se de acordo com, a propósito de". In: SOUSA SANTOS, Boaventura (org.). Trabalhar o mundo: os caminhos do novo internacionalismo operário. Rio de Janeiro: Civilização Brasileira, 2005.

MERCOSUL. Acordo multilateral de seguridade social do mercado comum do sul. Montevidéu: Mercosul, 1997.

MERCOSUL. Declaração Sociolaboral de 2015. Brasília, DF: Mercosul, 2015.

MERCOSUL. Tratado de Assunção. Tratado para a Constituição de um

Mercado Comum entre a República Argentina, a República Federativa do Brasil, a República do Paraguai e a República Oriental do Uruguai. Assunção: BCB, 1991.

OLIVEIRA, Lourival José de. A proteção do trabalho humano em um mundo globalizado: a criação de espaços públicos para a proteção de direitos fundamentais. Revista Direito UFMS, Campo Grande, v. 1, n. 1, p. 137-163, jul./dez. 2015. Disponível em: http://seer.ufms.br/index.php/revdir/ article/view/644. Acesso em: 7 jun. 2018.

OMAN, Charles. Globalisation et régionalisation: quels enjeux pour les pays em développement? Paris: OCD, 1994.

STUART, Ana Maria. A sociedade civil na integração: movimentos sociais e organizações sindicais. In: CHALOULT, Yves; ALMEIDA, Paulo Roberto de (org.). Mercosul, Nafta e Alca: a dimensão social. São Paulo: LTr, 1999. 
VEIGA, João Paulo Cândia. Práticas sindicais e acordos preferenciais de comércio: um novo caminho para o sindicalismo? In: CHALOULT, Yves; ALMEIDA, Paulo Roberto de (org.). Mercosul, Nafta e Alca: a dimensão social. São Paulo: LTr, 1999.

VIGEVANI, Tullo; MARIANO, Karina L. Pasquariello. Estratégias e alianças entre os atores sociais. In: CHALOULT, Yves; ALMEIDA, Paulo Roberto de. Mercosul, Nafta e Alca: a dimensão social. São Paulo: LTr, 1999.

VIGEVANI, Tullo. Mercosul: impactos para trabalhadores e sindicatos. São Paulo: LTr, 1998.

WANDERLEY, Luís Eduardo W. Sociedade civil, integração regional e Mercosul. In: WANDERLEY, Luís Eduardo W.; VIGEVANI, Tullo. Governos subnacionais e sociedade civil: integração regional e Mercosul. São Paulo: EDUC: Fundação Editora da UNESP: Fapesp, 2005.

ZYLBERSTAJN, Hélio et al. Processos de integração regional e a sociedade: o sindicalismo na Argentina, Brasil, México e Venezuela. Rio de Janeiro: Paz e Terra, 1996. 